\title{
Decentralized Governance in the Management of Urban Health Care Systems in Developing Countries
}

\author{
Joseph Okeyo Obosi \\ Department of Political Science \& Public Administration, University of Nairobi, Nairobi, Kenya \\ Email: jobosi@uonbi.ac.ke
}

How to cite this paper: Obosi, J. O. (2019). Decentralized Governance in the Management of Urban Health Care Systems in Developing Countries. Open Journal of Political Science, 9, 189-202.

https://doi.org/10.4236/ojps.2019.91010

Received: December 11, 2018

Accepted: January 18, 2019

Published: January 21, 2019

Copyright $\odot 2019$ by author(s) and Scientific Research Publishing Inc. This work is licensed under the Creative Commons Attribution International License (CC BY 4.0).

http://creativecommons.org/licenses/by/4.0/

\begin{abstract}
Enhanced Health care services address not only one of the key Sustainable Development Goals (SDG) which is goal No 3, but also the development strategies for most developing countries. Good governance is critical to improving health care systems. Many developing countries therefore have decentralized health care systems as a way of improving good governance and as a means of attaining improved access to and delivering quality health care services to both urban and rural population. Decentralization involves the extent of planning, management and decision making from national to lower levels of government. From the 1990s the capacity of governments in developing countries to deliver public goods and services was stretched to the extent there was dire for partnerships. The Public Private Partnerships (PPP) therefore became fundamental in the provision of health services under decentralization. The nature of PPP differed from country to country and the level of decision making within each level of government. The paper has discussed the extent to which decentralized governance has facilitated the management of health care systems in the urban centres through Public Private Partnership initiatives, by conducting a comparative case study analysis of existing literature on urban health care systems under different forms of decentralized governance in Kenya, Uganda, Ghana and India, respectively. The study established that access to health care services differed with forms of decentralization. Secondly, there were more public private partnerships in devolved governments which also registered higher improvement in access to health care services in urban centres. The paper concluded that the more the involvement of public private partnership, the better health care services in terms of access was noted.
\end{abstract}




\section{Keywords}

Public Private Partnership, Health Governance, Health Policy, Urban Health Care Systems, Decentralization

\section{Introduction}

The urban population in developing countries has moved from $1 / 4$ in 1965 to $1 / 2$ in 1990 , and is projected to be $2 / 3$ of the total population by the year 2025 (World Bank, 1992). The increasing population has equally been facing constraints in service delivery health being one of them. In the last two decades, most countries have focused on the democratization of decision making processes to enable the overstretched state to reengineer itself for the new demands (Bossert \& Beauvais, 2002). This was envisaged as a way of facilitating popular participation in decision making in development process (Rondinelli, 1981). This has been consistent with the New Public Management Paradigm. Decentralization has become part of the New Public Management (NPM) paradigm whose main purpose is to reduce differences between private and public sectors and shift from process to results based accountability (Hood, 1995). The NPM applied the doctrines of disaggregation of public sector organizations in corporatized units, engaged more contracts based on competitive provisions, stressed on private sector styles of management practice, and emphasized on discipline and frugality in resource use. Other doctrines of NPM included visible hands on top management, explicit measures of standards and success, and greater emphasis on output controls (Hood, 1995). The principles are based on the realization that neither the government nor the private sector could effectively and efficiently deliver public services singly, hence the establishment of public private partnerships.

A health care system is a set of activities and actors whose principal goal is to improve health through the provision of public and private medical services. Since the WHO 2000 report, systems' thinking has re-emerged as the cornerstone for improved health outcomes, and the consequent paradigm shift in policy making from disease specific initiatives to strengthening of health system (Panda \& Thakur, 2016). This was further strengthened by the WHO) report which explicitly recognized governance as a key pillar of health system building blocks framework. The significance of a decentralized governance of health systems is to improve decision making at local levels in different tiers of health service delivery and to ensure a constantly growing involvement at several levels of government as well as the private sector (Lama-Rewal, 2011). It is in this respect that the World Development report appreciated partnerships in the form of investment in the health sector by both bilateral and multilateral donors like UNICEF, USAID, World Bank support of projects (World Bank, 1993).

The current discourse supporting decentralization, primarily carried by the 
World Bank and adopted, with local variations, in a majority of countries in the past two decades, argues that one of its main impacts is to make the administration more responsive to people's needs (Lama-Rewal, 2011). Public Private Partnerships (PPPs) do not occur uniformly, it can take a form or a combination that exists in a continuum ranging from Public Enterprises at the weakest and private venture at the other end (Obosi, 2015). In the health sector, Public Private Partnerships (PPP) began in earnest with the 1993 World development report which invited donors, investment in health institutions to improve service delivery as a complement to the role of the state in so far as fiscal, administrative and political authority was concerned. The impact of PPP on health systems depended on the level of political, administrative and fiscal responsibilities bestowed upon a health management institution by the state government. There arose need for increased medical facilities, more medical staff, cost of medicare, expenditure by the government and public participation in decision making. Most governments therefore put in efforts to ensure that the services are delivered to the citizens whether in urban or in rural areas. The management of the health care especially in urban centres has mainly depended on the mode of governance put in place. The type of health governance in urban centres has depended on the type of system of government in each country with specific reference to latitude of decision making allowed for each authority.

The decision making levels has been associated with the extent of decentralization in every country. As a New Public Management tool, decentralization has been implemented differently ranging from deconcentration, delegation to devolution. The decentralization in each case has both defined the role of the state and other actors in the delivery of health services in both urban rural areas. Whereas in devolved systems the management of urban healthcare falls under the devolved unit in whatever name it is called, in delegated and deconcentrated systems, the national governments manage the healthcare in various ways. In this process, the role of the state influences the role of other stakeholders resulting in different forms of public private partnerships.

The public private partnerships results in improvement of urban health care systems. However, this is realized differently in different countries. The paper wished to establish the influence of forms of decentralization on the public private partnerships in the urban health care. Which form of decentralization augurs well for urban health care?

The argument therefore is that devolution creates a conducive environment for public private partnerships which in turn leads to improved access to health service provision. Countries with devolved systems of governance are likely to experience better health services than those which are either nationalized or deconcentrated.

Does this explain why different countries of relatively similar economic levels have different levels of urban health care services? How much does the existing health policies in the countries facilitate public private partnerships in urban health care? How does the PPP translate into improved health service delivery? 
How does the form or level of decentralization influence PPP in an urban health system? Under what form of decentralization does PPP flourish and which one threatens the operations of PPPs?

\section{Methodology}

A comparative case study was purposively conducted. Analysis of policies governing urban health care systems in Kenya, Uganda, Ghana and India was done. The choices of the four countries were prompted by the fact that each of the countries have different forms of decentralization, which have also been implemented differently. Whereas health services are mainly a devolved function in Uganda, it is devolved to local governments. In Ghana it is deconcentrated by the national government to a unified bureaucratic hierarchy of Ghana Health Service (GHS). Whereas in Kenya it is a devolved function to county governments except for national referral hospitals which are delegated functions, in India, it is a delegated function of state governments and not that of the national government which only retains the authority for broad policy guidelines. Uganda and Kenya exhibit variants of devolution. Whereas, devolution in Uganda is implemented through the local government Act therefore making the districts the implementing agency and to some extent operating as an agent of the national government, in Kenya, the health service function is fully devolved to the county governments which are independent in as far as implementation of the health services are concerned

The focus of analyses was on the functions of decentralized government units on the health care provision, the involvement of private sector in the urban health, singly or in partnerships with the state agency, intergovernmental relations in healthcare provision, and the impact of PPP on urban health care in the countries stated. The analysis was based on the structures established by each country to manage healthcare functions under respective jurisdictions with respect to the nature and capacity of the interactions amongst the relevant stakeholders in the health sector.

\section{Analytical Framework}

The paper has adopted the New Public Management Approach. The paper assumes that decentralization opens up decision making space through which public private partnerships can flourish. The greater the decentralization, the greater the decision space and the better the involvement of public private partnerships in service delivery processes. In as much as the paper borrows from the Bosserts framework of Decision space analysis (Bossert \& Beauvais, 2002), it differs from it in the context that he considers the decentralized units as agents implementing the decisions of the national government, as the Principal. Whereas the national government could be treated as a Principal with regard to delegation and deconcentration forms, the same could not be said of the devolved forms in which the unit is not answerable to the national government in terms of 
its deliverables. It is in this context in which the study adopts the New Public Management Paradigm in which the delivery of health care services is envisaged in the context of a new way of delivering public services through disaggregated units and in cooperating private sector models and partners (Hood, 1995; Osborne, 2006).

Decentralization aims at improving inputs, management processes and health outcomes, and has political, administrative and financial connotations. The argument is that the robustness of a health system in achieving desirable outcomes is contingent upon the width and depth of the "decision space" at the local level. To this end, different approaches and theories have been applied to appraise the components of the governance in health care systems, in the context of decentralization. In the emerging "continuum of health services" model, the challenge lies in identifying variables of performance which include: fiscal allocation, autonomy at local level, perception of key stakeholders, service delivery and outputs through the prism of decentralization in the first place, and in establishing directed relationships among them.

In the health system, the discourse of decentralization hinges on whether or not decentralized governance can create opportunities through which stated goals of efficiency, equity and quality of health services could be achieved . Public Private Partnerships provide avenues in which the participation of partners of different competencies are invoked within the decision space at local levels, for example, in financial allocation, organizational design, and human resources deployment. The decision space approach defines health system functions and their sub-functions, and the range of choice exercised by officials at different levels of the health system for these functions (Sreeramareddy \& Sathyanarayana, 2013).

The assumption was that the different latitudes of administrative, fiscal and political responsibilities assigned to each level of decentralization determines its porosity to public private partnerships. Devolution, with all the three responsibilities, has more opportunities for public private partnership engagements while deconcentration has the least as shown in Table 1. The delegation form oscillates between the two other forms and efficiency depends on the whims of the national government. The converse is also true. The deconcentration form is likely to pose more threat to public private partnerships than devolution. Whichever form is chosen by a given government, decentralization is deemed to be capable of ensuring accountability to local communities and stakeholders which when coupled with institutional capacity building is expected to translate into improvements in the lower level health systems.

\section{Decision Making Space in Decentralized Governance Systems}

The level of decision making in a governance system is dependent on the space which is assigned between the national and the decentralized governments. De- 
cision making space implies latitudes or opportunities to make choices and carry out certain responsibilities. Decentralization may take any of the three forms: Deconcentration, delegation or devolution. The decentralized units assume different names in different countries and to a large extent is a function of the level of government. In Kenya, they are known as Counties; Ghana and Uganda they are known as districts while in India there are state governments. Similar names do not necessarily imply similar functions. A district in Uganda which operates under a devolved system has more responsibilities than a district in Ghana which functions under a deconcentrated regime. Neither is the devolved districts in Uganda having similar responsibilities as devolved county governments in Kenya which are more autonomous in terms of decision making with regard to revenue and expenditure assignation. In India although the state governments operate as delegated systems from the national government, they do have more decision making in terms of disbursements to lower levels under it down to the village administration. In all the countries, the general health policy guidelines are given by the national governments.

Decentralization of the health services in many low and medium income countries has mostly occurred as a response to the primary healthcare approach promoted by international agencies such as the World Health Organization (WHO) and the United Nations Children's Fund (UNICEF).

Health system decentralization has been implemented in different forms and to different extents depending on the existing political and public administrative structure of the country and the organization of the health system itself (Sreeramareddy \& Sathyanarayana, 2013). The management of urban health care is therefore subsumed in the local governance system in each country such that they are responsible for healthcare in the urban areas under their jurisdiction save for referral hospitals which mostly fall under the national government. The success however depends on how much decision a decentralized unit can make in terms of resources mobilization and alignment with the key stakeholders, both in public and private sectors and the intergovernmental relations as shown in Table 1.

Table 1 shows that there is a maximum decision making space in a devolved system as it involves more decentralized decision making with the designated authorities which could be called state, regional, municipal or even county governments. The agencies are independent and not only raise their own revenues but also employ their own staff. The devolved units also have clear distinct legal, administrative and geographical jurisdictions. However the deconcentration system of governance has minimum decision making space due to restricted responsibilities. It neither enjoys fiscal nor political responsibilities as it is under direct control of central government.

Delegated system of governance enjoys moderate decision space as it is midway between deconcentration and devolution in which case it enjoys both administrative and fiscal responsibilities but not political. The authorities are 
semi-autonomous with supervisory power from central government hence being indirectly controlled by it.

\section{Public Private Partnerships in Comparative Health Governance Systems}

There are three different levels of decision making; minimum, moderate and maximum, which are implemented differently by different countries. Each of the levels is manifested by the type of responsibility each country attaches to the decentralized unit thereby affecting the governance of healthcare services. Table 2 shows a framework of decision levels in different forms of decentralization in Ghana, India, Uganda and Kenya.

Table 1. Showing logical framework of decision levels in different forms of decentralization.

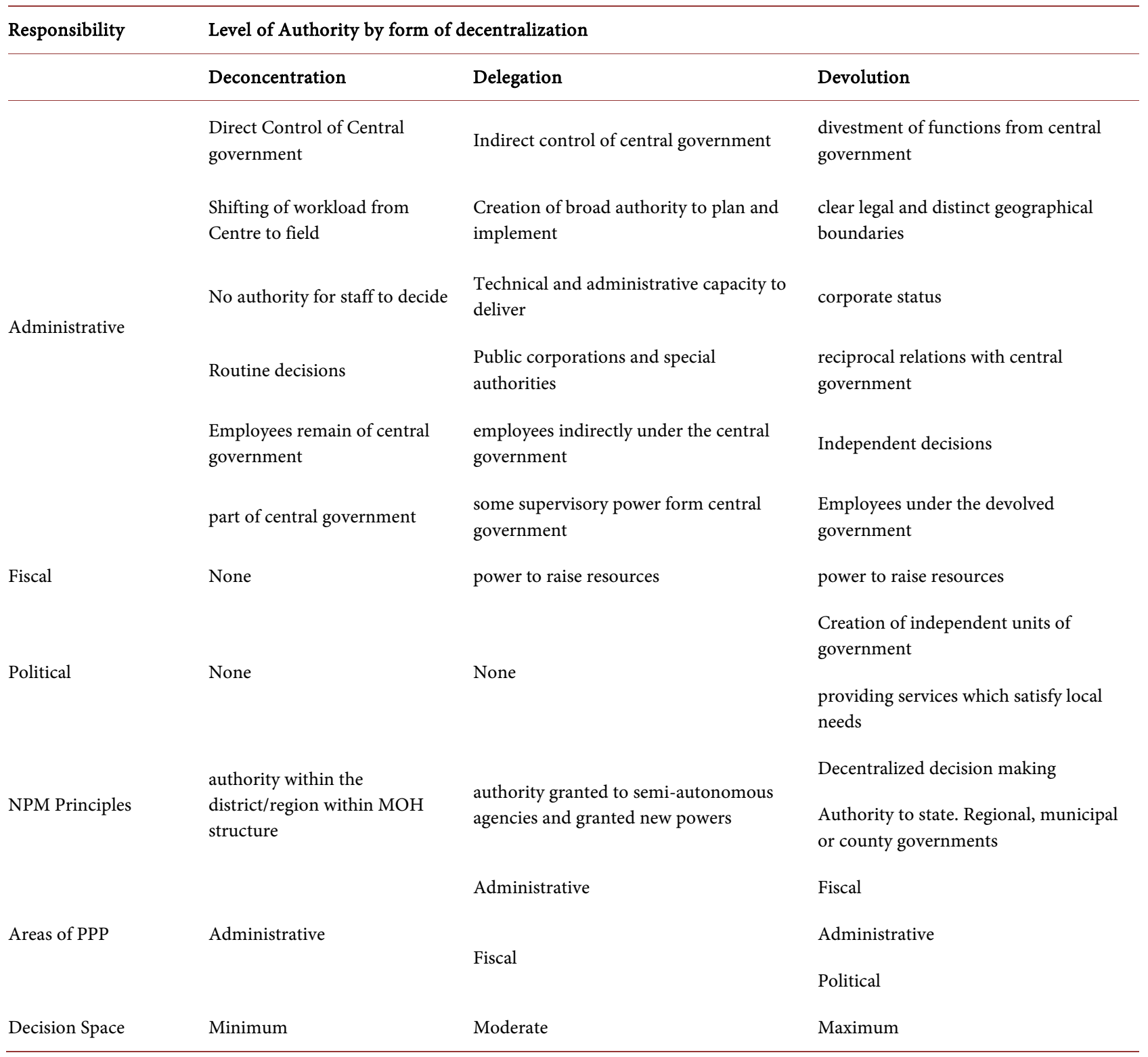


Table 2. Logical framework of decision levels in different forms of decentralization by country.

\begin{tabular}{|c|c|c|c|c|}
\hline \multirow[t]{2}{*}{ Responsibility } & \multicolumn{4}{|l|}{ Country } \\
\hline & Ghana & India & Uganda & Kenya \\
\hline \multirow{5}{*}{ Administrative } & $\begin{array}{l}\text { Unified bureaucratic hierarchy } \\
\text { of Central government }\end{array}$ & $\begin{array}{l}\text { Indirect control by central } \\
\text { government }\end{array}$ & $\begin{array}{l}\text { divestment of functions from } \\
\text { central government }\end{array}$ & $\begin{array}{l}\text { divestment of } \\
\text { functions from central } \\
\text { government }\end{array}$ \\
\hline & $\begin{array}{l}\text { Shifting of workload from } \\
\text { centre to field }\end{array}$ & $\begin{array}{l}\text { Public corporations and special } \\
\text { authorities }\end{array}$ & $\begin{array}{l}\text { clear legal and distinct } \\
\text { geographical boundaries }\end{array}$ & $\begin{array}{l}\text { clear legal and distinct } \\
\text { geographical boundaries }\end{array}$ \\
\hline & No authority for staff to decide & $\begin{array}{l}\text { Creation of broad authority to } \\
\text { plan and implement }\end{array}$ & corporate status & Independent decisions \\
\hline & Routine decisions & $\begin{array}{l}\text { some supervisory power form } \\
\text { central government }\end{array}$ & Special authorities & $\begin{array}{l}\text { reciprocal relations with } \\
\text { central government }\end{array}$ \\
\hline & $\begin{array}{l}\text { Employees indirectly under } \\
\text { central government }\end{array}$ & $\begin{array}{l}\text { employees indirectly under the } \\
\text { state government }\end{array}$ & $\begin{array}{l}\text { employees indirectly under the } \\
\text { central government }\end{array}$ & $\begin{array}{l}\text { Employees under the } \\
\text { devolved government }\end{array}$ \\
\hline Fiscal & None & power to raise resources & power to raise resources & power to raise resources \\
\hline Political & None & $\begin{array}{l}\text { Vibrant Semi-autonomous } \\
\text { units of government }\end{array}$ & $\begin{array}{l}\text { Vibrant semi-autonomous } \\
\text { units of government }\end{array}$ & $\begin{array}{l}\text { Vibrant independent } \\
\text { units of government }\end{array}$ \\
\hline \multirow[b]{2}{*}{ NPM Principles } & $\begin{array}{l}\text { Deconcentrated decision } \\
\text { making }\end{array}$ & Delegated decision making & Devolved decision making & $\begin{array}{l}\text { Devolved decision } \\
\text { making }\end{array}$ \\
\hline & $\begin{array}{l}\text { authority to GHS and districts } \\
\text { within Ministry Of Health } \\
\text { structure }\end{array}$ & $\begin{array}{l}\text { authority to State and City } \\
\text { Corporations }\end{array}$ & authority to District Councils & $\begin{array}{l}\text { authority to County } \\
\text { governments }\end{array}$ \\
\hline \multirow{3}{*}{ Areas of PPP } & \multirow{3}{*}{ Administrative } & Administrative & Fiscal & Fiscal \\
\hline & & \multirow{2}{*}{ Fiscal } & \multirow[t]{2}{*}{ Administrative } & Administrative \\
\hline & & & & Political \\
\hline Decision Space & Minimum & Moderate & Moderate & Maximum \\
\hline
\end{tabular}

\section{Ghana}

Ghana is a unified bureaucracy under the direct control of the national government. The health sector is therefore under the central government. All hospitals are directly controlled by the Ministry of Health through the Government Health Services (GHS) which is overseen by the National Governing Council and retains centralized control over its regions and districts (Bossert \& Beauvais, 2002). With the responsibilities administratively shifted to the field agencies and regulated through the autonomous GHS and semi-autonomous Budget Management Committees (BMC). The staff of GHS are no longer civil servants although it is still under administrative supervision of Ministry of Health. The government runs the public health services through GHS although it still recognizes and supports the parallel operations of private, traditional, and nongovernment providers; civil society; and community groups.

The PPP is realized to the extent that the government supports private mission hospital by seconding staff and essential equipment. The government also sub-contracts specific health services competitively based on their comparative 
advantage (ACCORD, 2009). There are also three types of insurance schemes under the existing national health insurance scheme; a District-Wide (Public) Mutual Health Insurance scheme through which the workers of the public sector directly pay a share of their wages into the health insurance system; a "Private Mutual Health Insurance scheme" through which subsistent farmers, people working in the informal sector and unemployed people who were not formerly employed in the public sector are to pay their contribution; and a "Private Commercial Health Insurance Scheme" through which those employed by larger companies and multi-national companies pay their contributions which takes care of outpatient treatment, admissions, medicines and referrals of patients within the approved list (ACCORD, 2009).

The health care system is divided into five tiers ranging from community level, sub-district, district, regional level and national level and involve collaboration and partnership with other agencies with impact on health outcomes. The Insurance payments including that of National Hospital Insurance Fund (NHIF) is centrally determined choice and mode of payments. Independent contracting with Churches Hospitals Association of Ghana (CHAG). The performance contracting is done with the supervising BMC. No space for popular participation in decision making

\section{India}

From 1992, Health services in India were delegated to the administrative districts of each of the 23 state governments (Kaur et al., 2012). The decentralization is three-tiered, namely village, sub-division and division levels and are responsible for the management of each local health institutions. Several societies that used to sponsor health care centrally were merged under each District Health Society.

The governance of health care systems in India is at all the three levels of government: the central (or Union) government; the government of the National Capital Territory of Delhi (or Delhi government); and the Municipal Corporation of Delhi (MCD). At the topmost level is a major hospital such as the All-India Institute of Medical Sciences. Institutions such as the Indian Council for Medical Research and dispensaries catering only to the needs of specific clients (i.e. government employees) come under the central government.

At the state level, a number of hospitals, polyclinics, dispensaries and medical colleges function under the Delhi government. That government operates through the Social Welfare Department and the Health and Family Welfare Department, whose Health Directorate coordinates the action of the different health service providers (including private providers), in order to avoid overlaps and to control the quality of services.

The MCD also manages a series of hospitals, polyclinics, dispensaries, maternity and child welfare centres, mobile vans and primary health care centres. The MCD operates through its Health Department and its Slum and Jhuggi Jompri 
(huts) Wing, which caters to the poorest section of the population.

In addition, various parastatal agencies such as the Northern Railways or the Employees of the State Insurance Corporation (ESI) also provide medical facilities catering for their exclusive clientele. Lastly, the voluntary sector runs a few charitable hospitals. To complicate matters, dispensaries (and hospitals to a lesser extent) provide different types of medicine: besides allopathic dispensaries, one finds ayurvedic and unani dispensaries ("Indian systems of medicine") as well as homeopathy. The other two civic bodies-the New Delhi Municipal Council and the Delhi Cantonment Board-are also health care service providers for their respective constituencies.

With the population of India becoming increasingly centred in cities, the government efforts to strengthen urban health systems have focused on programmes such as the National Urban Health Mission. In 2000, four out of the seven hospitals that had been taken over by the Delhi government went back to the MCD (Lama-Rewal, 2011). In urban India the health system is highly diverse, ranging from private health care services to public health care to traditional healers. However, the private health sector has gained increasing importance and has grown quickly in recent years (Subramanian, Butsch, \& Sakdapolrak, 2012). According to National Family Health Survey-3, the private medical sector remains the primary source of health care for $70 \%$ of households in urban areas and $63 \%$ of households in rural areas.

The governance of the health care system is therefore problematic and shows overlaps. For example, within the elected governments for the National Capital Territory of Delhi and for the Municipal Corporation of Delhi, there exists a multiplicity of agencies which work in the same territory, under the responsibility of different levels of government. Other actors who provide public health care services within Delhi's urban governance include civil society organizations, consisting essentially of neighbourhood associations and NGOs (Lama-Rewal, 2011). Neighbourhood associations, known in Delhi as "resident welfare associations" (RWAs), consist of a semi-formal grouping of neighbours concerned with the maintenance of local infrastructure, and have been in existence in Delhi at least since the 1960s. In 2000, the government launched the Bhagidari Schemewhich aimed to develop people's participation in the management of local affairs, as “citizens' groups” (Lama-Rewal, 2011).

However, most NGOs active in the field of health care are actually service providers hired by the central, state or municipal administration to implement a number of schemes pertaining to public health implying that they have a limited decision space in as much as majority of urban dwellers display a preference for the private sector due to perceived efficiency despite the fact that public health care is free (Lama-Rewal, 2011). The fact that most NGOs have become implementers of government programmes can be seen as a new form of centralization, strengthening the position of senior bureaucrats and by-passing the elected politicians (Lama-Rewal, 2011). 


\section{Uganda}

Uganda has from 1986 been governed through a five tier Local Councils ranging from Village, Parish, Sub County, County and District levels (Green, 2010). Responsibilities are deconcentrated from the national government to the local councils. Although the Local councils elect their own leaders, the president appoints the chairman of LCV (District) while the minister for local Government appoints its secretary. The local councils are supposed to collect taxes and remit to the District Government which in turn is not only expected to share the financial resources together with its own tax collections with the lower governments. Each decentralized unit is supposed to take care of its development and delivery of services (all except security, foreign affairs, national planning and immigration) using the locally generated taxes with expected similar amount of tax revenue being complemented by the Central government. Health services is therefore one of the decentralized functions performed by the higher local governments (Green, 2010). The donors have therefore opted to bypass the central government and send funds/grants directly to the districts though not to the lower decentralized units.

All hospitals except two referral hospitals are run by District (devolved) Councils. Unlike in Ghana, health directors sit on district health committees, determined at district level. There is more autonomy and level of fee-payment choices. The Distinct Councils are allowed to contract out services to NGO and missions. The Mission run health faculties account for $1 / 5$ of health facilities in the country. The NGOs are perceived to be providing better services at lower cost than the public hospitals and are responsible for $38 \%$ of the beds but account for $54 \%$ of bed days; Bed occupancy rate is $90 \%$ compared to $40 \%$ of public hospitals. In terms of performance contracting, each district has its own decision space in which popular participation is realized through District health committees and Health Unit Management Committee (Bossert \& Beauvais, 2002).

\section{Kenya}

The governance of Health care systems in Kenya could be categorized into two levels of government; National and County governments. Whereas the former is concerned with the national referral health facilities and health policy formulation and implementation, the county governments are in charge of the management of health care at the county levels. Health is a devolved function. The County health services include: County health facilities and pharmacies; Ambulance services; Promotion of primary health care; Licensing and control of undertakings that sell food to the public; Veterinary services (excluding regulation of the profession); Cemeteries, funeral parlours and crematoria; and Refuse removal, refuse dumps and solid waste disposal. Devolved governments manage up to level 4 hospitals while national government manage the 2 referral hospitals. 
In terms of the medical services, the choice is limited ranging from individual to national governments. The individual decisions range from personal payments to Insurance covers, while that of the national government is done through the National Hospital Insurance Fund (NHIF). There are several insurance firms selling health policies to individuals and corporates depending on specific choice of packages on offer. This therefore puts the responsibility of health management in Kenya to both state and private managers, which includes AAR, Jubilee Insurance, Alexander Forbes Healthcare, Avenue Healthcare, Britam insurance, UAP, Resolution insurance, CIC, First Assurance, Heritage and Trident.

Membership to the National Hospital Insurance Fund is compulsory to all salaried employee with voluntary membership to those in self-employment. Contributions range from Ksh 320 to a maximum Ksh 1700. When members or their declared dependants fall ill and are admitted in accredited hospitals, they are only required to pay the balance of the bill after the rebate has been calculated. The rebate varies depending on the hospital status and ranges from ksh 400 to ksh 2000 per day. Whereas the national government manages NHIF, the county governments are responsible for the running of the heath care system including the hospitals under their jurisdiction, hence possible conflict in terms of decision making.

The governance of the health care system comprises the public system, with major players including the $\mathrm{MOH}$ and parastatal organizations, and the private sector, which includes private for-profit, NGO, and FBO facilities. Health services are provided through a network of over 4700 health facilities countrywide, with the public sector system accounting for about 51 percent of these facilities. The public health system consists of: national referral hospitals, provincial general hospitals (Level five), district hospitals (Level four), health centres, and dispensaries.

National referral hospitals are at the apex of the health care system, providing sophisticated diagnostic, therapeutic, and rehabilitative services. The two national referral hospitals are Kenyatta National Hospital in Nairobi and Moi Referral and Teaching Hospital in Eldoret. The equivalent private referral hospitals are Nairobi Hospital and Aga Khan Hospital in Nairobi. Although several health-oriented NGOs operate throughout the country, the population covered by these NGO health services cannot be easily determined. The MOH and external donors support the health services offered by NGOs and the private sector in several ways.

In 2015, the Kenyan Government selected GE Healthcare as one of its main partners to deliver a seven-year Managed Equipment Services Partnership (MES) to provide Kenya's 46 million strong population with access to teleradiology services across 98 Ministry of Health hospitals in Kenya's 47 counties. An MES is a form of PPP that enables customers to adopt a "pay for service" expenditure plan and affords a number of financial benefits including funding to cover equipment, maintenance and other project costs such as training. The aim 
of this partnership was to increase access to affordable healthcare for all and enable earlier diagnosis and treatment of various diseases.

Table 2 shows that different countries have implemented differently the decentralization of the health governance. Whereas there is divestment of functions from central government to decentralized units in Kenya and Uganda, the national government of India has indirect control over local health functions whereas in Ghana, the health function is a bureaucratic hieracrchy if the central government.

The table further shows that whereas in Ghana there are no fiscal roles, decentralized governments in India, Uganda and Kenya have powers to raise resources to facilitate health services.

Uganda and Kenya have devolved decision making to district council authorities and country governments, respectively; India has delegated decagon making to state and city corporations while Ghana has deconcentrated decision making authority to Government Health Services and districts within the ministry of Health structure. Of the four countries, only Kenya has PPP in administrative, fiscal and political areas. Uganda and India have PPP in fiscal and administrative areas while Ghana has PPP in administrative areas only. The decision making space is therefore maximum in the case of Kenya, while moderate in both Uganda and India Systems and minimum in Ghana.

\section{Conclusion}

There is no uniform "fit it all" strategy to fix urban health care management. Different countries of different regime types have used different strategies with different results. Although it has emerged that the decentralization of healthcare is commonly accepted amongst the countries as the best option even though similar forms of decentralization applied in different countries have sometimes yielded contrasting results. No country has specific governance systems for urban health care only but is governed under the national policy within the existing governance structure under which the urban centres fall. Notwithstanding the differences, there is need to sensitize governments and academia about how public private partnerships can be facilitated through "shared governance" to benefit policy making and its effect on the entire spectrum of health system, with special emphasis on efficiency, community participation, human resource management and quality of services. The decentralization of the governance of health system can be both a threat and an opportunity for public private partnerships. The best opportune position is with the devolved form of decentralization in which more actors have both access and greater decision making space. However, deconcentration form of decentralization is a threat to PPP since the decision making space is constrained. Even more democratic governments like India tend to recentralize decision making which ultimately locks out some critical segments of partners in the decision making with a thin difference compared to less democratic countries like Uganda. 


\section{Conflicts of Interest}

The author declares no conflicts of interest regarding the publication of this paper.

\section{References}

ACCORD (2009). Health Care in Ghana.

Bossert, T. J., \& Beauvais, J. C. (2002). Decentralization of Health Systems in Ghana, Zambia, Uganda and the Philippines: A Comparative Analysis of Decision Space. Health Policy and Planning, 17, 14-31. https://doi.org/10.1093/heapol/17.1.14

Green, E. D. (2010). Decentralisation and Conflict in Uganda Decentralization and Conflict in Uganda.

Hood, C. (1995). The "New Public Management" in the 1980s: Variations on a Theme. Accounting Organizations and Society, 20, 93-109. https://doi.org/10.1016/0361-3682(93)E0001-W

Kaur, M., Prinja, S., Singh, P. K., \& Kumar, R. (2012). Decentralization of Health Services in India: Barriers and Facilitating Factors. WHO South-East Asia Journal of Public Health, 1, 94-104. https://doi.org/10.4103/2224-3151.206920

Lama-Rewal, S. T. (2011). Urban Governance and Health Care Provision in Delhi. Environment and Urbanization, 23, 563-581. https://doi.org/10.1177/0956247811416433

Obosi, J. O. (2015). The Public Service Delivery Challenge: A Public Private Partnership in Water Service Provision in Kenya. Saarbrucken: Schaolars' Press. http://www.omniscriptum.com

Osborne, S. P. (2006). The New Public Governance? Public Management Review, 8, 377-388. https://doi.org/10.1080/14719030600853022

Panda, B., \& Thakur, H. P. (2016). Decentralization and Health System Performance-A Focused Review of Dimensions, Difficulties, and Derivatives. BMC Health Services Research, 16, 1-14. https://doi.org/10.1186/s12913-016-1784-9

Rondinelli, D. A. (1981). Government Decentralization in Comparative Perspective: Theory and Practice in Developing Countries. IRAS, 2, 133-146. https://doi.org/10.1177/002085238004700205

Sreeramareddy, Ct., \& Sathyanarayana, Tn. (2013). Decentralised versus Centralised Governance of Health Services (Protocol).

Subramanian, S., Butsch, C., \& Sakdapolrak, P. (2012). Urban Health in India. Internationales Asienforum, 43, 13-32.

World Bank (1992). Water World Development Report 1992. Development and the Environment.

World Bank (1993). World Development Report: Investing in Health. Washington DC: Oxford University Press. 